\title{
Review: some behavioural interventions, drugs, and dietary changes reduce infantile colic
}

Lucassen PL, Assendelft WJ, Gubbels JW,et al. Effectiveness of treatments for infantile colic: systematic review BMJ 1998 May 23;316:1563-9.

\section{Question}

What is the effectiveness of diets, drug treatment, and behavioural interventions for infantile colic?

\section{Data sources}

Studies were identified by searching Medline (1966-96), EMBASE/Excerpta Medica (1986-95), and the Cochrane Controlled Trials Register with the terms colic and crying. Bibliographies of relevant studies were scanned.

\section{Study selection}

Published studies on the treatment of infantile colic were selected if reduction in crying or colic was the main outcome measure. Exclusion criteria were publication in abstracts or letters, infants with a normal pattern of crying or whose mothers had not complained about the crying, infants $\geqslant 6$ months old, $<3$ days treatment, or no control group.

\section{Data extraction}

Data were extracted on age, sex, age at onset of infantile colic, number of hours of crying each day, proportions of breast fed and firstborn infants, dropout rates, effect sizes, quality scores (maximum 5 points), and family history of atopy.

\section{Main results}

27 trials met the selection criteria. The median quality score was 3 (range 0-5). The following interventions were effective for reducing excessive crying: elimination of cows' milk protein (5 trials); herbal tea containing chamomile, vervain, liquorice, fennel, and balm mint (1 trial); anticholinergic drugs (dicyclomine or dicycloverine in 5 trials); and advice to reduce stimulation and leave the infant when the caregiver found the crying intolerable ( 1 trial) (table). Replacing cows' milk with hypoallergenic formula milk (2 trials) reduced crying (weighted effect size $0.22,95 \%$ CI 0.09 to 0.35), whereas using soy formula milk (3 trials) did not. 8 of 177 infants treated with a normal dose of dicyclomine and dicycloverine had adverse events. Increasing parental responsiveness was more effective than replacing cows' milk protein with hypoallergenic formula milk in 1 trial (table). Interventions that were not effective for reducing crying were lowering the lactose content in formula milk (2 trials), adding fibre to formula milk ( 1 trial), simethicone treatment (3 trials), and increased carrying of infants (1 trial). Specific management techniques to soothe infants plus general information and reassurance were less effective than general information and reassurance in 1 trial (table).

\section{Conclusions}

Elimination of cows' milk protein, drinking herbal tea, use of anticholinergic drugs (specifically dicyclomine), and advice to decrease stimulation reduce excessive crying in infantile colic. Low lactose or fibre enriched formula milk, simethicone, and increased carrying of infants do not reduce excessive crying.

Interventions for reducing excessive crying in infantile colic

\begin{tabular}{|c|c|c|}
\hline Comparisons & $\begin{array}{l}\text { No of } \\
\text { studies }\end{array}$ & Effect size (95\% CI) \\
\hline Eliminating cows' milk protein $v$ control & 5 & $0.22(0.10 \text { to } 0.34)^{*}$ \\
\hline Herbal tea $v$ control & 1 & $0.32(0.10$ to 0.54$)$ \\
\hline Anticholinergic drugs $v$ control & 5 & $0.46(0.33 \text { to } 0.60)^{*}$ \\
\hline Reduced stimulation $v$ control & 1 & $0.48(0.23$ to 0.74$)$ \\
\hline $\begin{array}{l}\text { Parental responsiveness } v \text { no cows' milk } \\
\text { protein }\end{array}$ & 1 & $0.30(0.06$ to 0.55$)$ \\
\hline $\begin{array}{l}\text { Soothing techniques and information } v \\
\text { control }\end{array}$ & 1 & $-0.37(-0.69$ to -0.05$)$ \\
\hline
\end{tabular}

*Effect sizes are weighted.

Source of funding: in part, Praeventie Fonds.

For correspondence: $\operatorname{Dr} P$ L Lucassen, Akkerroosstraat 18,5761 Ex Bakel, the Netherlands. Fax +31 492343975.

A modified version of this abstract appears in Evidence-Based Medicine.

\section{Commentary}

Infantile colic can cause considerable distress to a family. The average infant cries for 2-3 hours/day, whereas the infant with colic usually cries for $>4$ hours/day and appears to have severe abdominal pain. ${ }^{1}$ Parents often must deal with the child's behaviour while sifting through a maze of conflicting suggestions from well meaning friends and family.

Lucassen et al reviewed the published evidence that evaluates the effectiveness of all diets, drug treatments, behavioural interventions, and other treatments for infantile colic. In their comprehensive review, the authors used a highly sensitive search strategy and extensive reference checking. They also repeated the metaanalysis after removing trials that scored low in methodological quality.
This review is limited by its exclusion of unpublished studies. Herbal teas are presented as an effective treatment but only 1 article is included to support this strategy. The usefulness of this intervention is also limited by the lack of a clear description of how tea is used (eg, how much, how often, how strong).

This review shows that anticholinergics, particularly dicyclomine, were effective; however, the considerable side effects (ie, breathing difficulties, seizures, syncope, asphyxia, muscular hypotonia, and coma) would severely limit their use in practice.

Further studies are required on dietary treatment, herbal teas, and modified anticholinergic drugs that do not have serious side effects.

Lucassen et al report a range of effective treatment choices. The noninvasiveness of most of the interventions allows parents to choose strategies that are conducive to their parenting styles and capabilities. The authors remind clinicians to investigate the obvious reasons for excessive crying before immediately labelling the behaviour as "colic." Once these have been ruled out, the healthcare provider can offer strategiesthat are evidence based and that are proved to be effective.

Wendy Goodine, RN(EC), BScN Primary Care Nurse Practitioner LAMP Community Health Centre Toronto, Ontario, Canada \footnotetext{
1 Cervisi J, Chapman M, Niklas B, et al.J Pediatr
Health Care 1991;5:184-90.
} 